\title{
Diablotexto
}

\section{"El adarve de la almena se ha vuelto gris". Ecos del soldado en el castillo interior de Blas de Otero}

"El adarve de la almena se ha vuelto gris". Echoes of the soldier in Blas de Otero's inner castle

\author{
JULIO SALVADOR SALVADOR \\ UNIVERSIDAD COMPLUTENSE DE MADRID
}

Resumen: Este artículo se centra en la aparición del motivo del castillo en el poema intimista "Diseminado", perteneciente a La galerna (1969-1974), poemario póstumo de Blas de Otero. Dicho símbolo posee una especial significación dentro del imaginario cultural de Occidente. Sin embargo, en "Diseminado" forma parte del campo ideológico o nocional de lo épico. Este presenta una connotación negativa derivada de los amargos recuerdos de Blas de Otero como soldado, la cual se puede rastrear en poemas sobre sus vivencias durante la guerra como "Imbatida juventud", de Que trata de España (1959).

Palabras clave: Blas de Otero, Castillo, Recuerdos del soldado, Intimismo, Campo nocional o ideológico.

Abstract: This essay focuses on the use of the castle as a leit motiv in the intimate poem "Diseminado", belonging to La galerna (1969-1974), Blas de Otero's posthumous book of poems. This symbol carries a special significance within the Western cultural imaginary. In "Diseminado", however, it belongs to the ideological or notional field of the epic and shows negative connotation derived from the amargo memories of Blas de Otero as a soldier, which can be traced in other poems related to his war time experience, such as "Imbatida juventud", from Que trata de España (1959).

Key words: Blas de Otero, Castle, Soldier Memories, Intimism, Notional or ideological field. 


\section{Introducción}

Es útil ahondar en los nexos que un filólogo puede $-\mathrm{y}$ ha de- establecer entre la literatura y otras disciplinas, como la lingüística o la historia. En muchas de las clases de "Semántica del español" que se imparten en las universidades españolas se explican las diferentes teorías sobre el significado. Algunas de estas hipótesis son denominadas "representacionalistas" o "mentalistas", y señalan que el significado sería la relación existente entre una expresión lingüística y una representación mental (Escandell Vidal, 2004: 39) ${ }^{1}$. Dicha relación se podría concebir como un concepto que recoge los rasgos esenciales y constitutivos de una entidad, o, el "conjunto de rasgos que comparten los elementos pertenecientes a un conjunto" (Abad Nebot, 2014: 191). Podría pensarse, por tanto, en el concepto de "castillo", el cual presenta algunas de las siguientes características en las definiciones recogidas en el diccionario de la Real Academia Española: lugar fuerte, que suele estar cercado de murallas o de otras fortificaciones... De ahí saldría una representación mental del hablante en la que las palabras tienen una relación directa con los entes u objetos significados. O dicho de otro modo: de la expresión se inferiría una imagen o representación mental (Escandell Vidal, 2004: 45). Al profundizar un poco más, también tendría importancia el concepto de "prototipo": "el prototipo de un predicado es un objeto que se considera muy típico de la clase de objeto a la que nos podemos referir mediante una expresión que contenga ese predicado" (Leech, 1985: 93). Así, el prototipo sería el mejor representante de una categoría (Kleiber ctd. en Abab Nebot, 2014: 182). Un modelo que a cualquier persona se le ocurriría es el siguiente: el prototipo de "mascota" sería el perro. El prototipo de "castillo", por ejemplo, podría ser el de la ciudad valenciana de Játiva, de estilo gótico. Y, si se hace un juego de traslación de conceptos de una disciplina a otra, quizás el prototipo

\footnotetext{
${ }^{1}$ No obstante, para otras escuelas, como la semántica estructura del lingüista rumano Eugenio Coseriu, el significado no es una relación. Es una de las caras del signo, cuya otra cara es el significante. Es la idea, el concepto que encierra un signo lingüístico, es decir, el conjunto de rasgos necesarios y suficientes para la identificación de tal concepto en el sistema de la lengua frente a cualquier otro concepto que pertenezca a ese mismo sistema. En definitiva, el significado sería un valor de lengua, $y$, tal y como se ha codificado o formalizado en una lengua determinada, corresponde no a un objeto particular, sino a una clase de objetos. Este concepto es social y, en ese sentido, objetivo (el código debe serlo, es condición de existencia de cualquier código social el ser compartido por sus usuarios).
} 
de literato que hable de los castillos sería Franz Kafka -una de sus obras más icónicas es la inacabada El castillo-, Jorge Luis Borges -habría que mencionar su conferencia "Pesadilla", dentro de la compilación Siete noches-, Umberto Eco -la biblioteca de la abadía benedictina a la que llegan Adso de Melk y Guillermo de Baskerville en El nombre de la rosa bien se asemeja a una laberíntica fortaleza del saber- o santa Teresa de Jesús -en Las moradas o El castillo interior se describen siete fases que constituyen los escalones que hay que superar para llegar a Dios, y su título refleja el simbolismo del castillo, trasunto de la Jerusalén celestial (Biederman, 1993: 95)-. Incluso, en tiempos más actuales, habría que mencionar al escritor Luis Zueco con su exitosa novela de corte histórico El castillo (2015).

A priori, no parece que pudiera aparecer en la lista de prototipos el nombre de Blas de Otero, ya que el poeta vasco, uno de los clásicos de la poesía española de mitad de siglo, no casa con el prototipo que, con seguridad, los lectores, los críticos y los especialistas tengan en la cabeza. Por ello, como en un primer momento la idea de interrelacionar al poeta vasco con los castillos resulta un tanto peregrina, se hace imprescindible justificar la relación que se propone. Hay, esencialmente, dos razones para la asociación: en primer lugar, porque el motivo del castillo aparece en "Diseminado", un poema de gran carga psicológica con el que se ahonda en los recovecos más íntimos del sujeto lírico, en su "castillo interior"2. Esa es la principal razón y la fundamental. En segundo lugar, porque se observa en Otero una construcción literaria que algo tiene que ver con la visión privilegiada que se tiene desde las alturas de un castillo. Una visión que radica en su experiencia de soldado, la cual en algunas composiciones llega a afectar al contenido de los textos, a su sentido ${ }^{3}$. A partir de estas dos premisas, en este artículo se procede a indagar

\footnotetext{
2 También cabría hablar del soneto "El castillo" (2013: 844), de Hojas de Madrid, pero daría para otro artículo, puesto que el guiño intertextual a Kafka sobrevuela por todo el texto.

3 "Sentido" en cuanto a la diferenciación que hace entre este y "significado" Coseriu, quien establecía que "el significado [...] es el contenido dado en y por una lengua como tal" (1978: 135) y el sentido "el plano semántico propio y exclusivo del «texto»" (1978: 136). Por lo tanto el significado, que está estructurado por la lengua, guarda una relación evidente con el concepto que cada hablante tiene sobre la realidad que el signo designa, pero este concepto individual e ilimitadamente variable sobre la realidad no afecta al valor de lengua. Más allá de "ese promedio conceptual" que se ha llegado a codificar en las palabras, existirían conceptos más o menos someros o profundos, sobre las cosas mismas. Eso dependería de la experiencia
} 
sobre cómo el poeta vasco desarrolla en algunas de sus composiciones una "retención" del pasado, noción basada en la intrahistoria acuñada por Miguel de Unamuno, que se reanaliza mediante la utilización de un léxico relacionado con lo militar o lo épico. Esto podría llegar a relacionarse con algunos atributos de la autoficción -aquellos textos que se caracterizan por la ficcionalidad del yo autobiográfico-, pues la literatura, como señala Ana Casas Janices, se convertiría en un mecanismo mediante el cual se podrían "ofrecer explicaciones -aunque personales y subjetivas- a los procesos sociales y políticos que operan en nuestras realidades y en nuestras vidas" (Casas Janices, 2016: 145). La importancia de la memoria y de la rememoración por parte de un poeta no se ha de confundir con que se deba abordar siempre el estudio de la literatura desde una perspectiva biográfica. Sin embargo, hay ocasiones en las que para entender mejor las motivaciones de un autor, hacer una retrospectiva biográfica es de utilidad para el especialista, y, por tanto, de interés para calibrar la creatividad generada mediante "la tensión entre lo referencial y lo ficcional" (Casas Janices, 2016: 145).

\section{El frente de batalla}

Resulta de interés saber que Blas de Otero fue el tercero de cuatro hermanos. Tal y como indican los estudiosos de la poesía oteriana, como Juan José Lanz, su familia formaba parte de la burguesía bilbaína (2016: 31), aunque habría que añadir un leve pero vital matiz. Esa preponderancia social la obtuvo su padre al ser un hombre que se hizo a sí mismo: de raigambre marinera, construyó la casa familiar y supo usar para su propio beneficio la neutralidad española durante la Primera Guerra Mundial, con lo que consiguió hacer florecer su negocio industrial (Fernández de la Sota, 2016: 40). El tipo de vida sin grandes problemas, consistente en veranos en San Sebastián o

directa o indirecta sobre la realidad, es decir, de los conocimientos del individuo, e incluso de sus percepciones subjetivas de ella. El sentido coseriano depende del significado, de la designación y de todos los factores que intervienen en la comunicación, incluido, naturalmente, el contexto en que se produce. 
improvisados viajes a Madrid, acabó de forma repentina en 1932. Blas de Otero debe coger las riendas del barco que se hunde, ya que en pocos meses mueren tanto su padre como su hermano mayor, por lo que se convierte en la única opción de sustento para su madre y sus dos hermanas (De la Cruz, 2013: 60). La obligación impone y Otero se saca en apenas dos años y medio la carrera de derecho (Lanz, 2016: 34), pero la presión le supera y comienzan sus primeras crisis nerviosas. Entre periodos de convalecencia en el hospital psiquiátrico de Usúrbil y otros de vigor anímico y físico, el poeta comienza a convertir la necesidad de contar con la poesía como medio de expresión personal en acción colectiva. Prueba de ello es el surgimiento, antes de la Guerra Civil, del grupo bilbaíno de la Asociación Libre de Ensayos Artísticos (Álea), de fuerte raigambre católica (De la Cruz, 2013: 61; Fernández De la Sota, 2016: 41), un grupo con el que Otero descubrió definitivamente su vocación poética y sus aficiones musicales. Estos años coinciden con su ferviente fe.

Sin embargo, su concepción del mundo basada en la religiosidad comienza a resquebrajarse con el estallido de la Guerra Civil: en los primeros compases de la contienda formó parte de un batallón vasco como sanitario (Fernández de la Sota, 2016: 41). La misión de contener a las fuerzas nacionales fracasa y, tras la caída de Bilbao el 19 de junio de 1937, Otero, ya parte del ejército nacional, es enviado al XII Regimiento de Artillería Ligera de Logroño (De la Cruz, 2013: 62), cuerpo militar que desempeñó un papel importante en el frente de Levante. Los hechos vividos y acaecidos durante la Guerra Civil le acompañarán durante toda su obra poética: bien todavía creyente, como en los años de composición del Cántico (1942), o ya anhelante y al mismo tiempo descreído de Dios, como en la época de Ángel fieramente humano (1947-1949); bien entregado a la causa política, en obras como En castellano (1951-1959), o bien apóstata de los grandes sistemas y confiando únicamente en los pequeños detalles de lo cotidiano, tal y como se desprende de su último volumen, conformado por Hojas de Madrid y La galerna (19681977). Poemas como "Juventud imbatida", dentro de su etapa de poesía social y perteneciente al poemario Que trata de España (1960-1964), basan su efectividad en la construcción bronca de unas imágenes sin excesiva carga 
retórica, y no en una larga relación de detalles espacio-temporales, para situar al lector camino a Levante desde poblaciones de la provincia de Teruel, pasando por localidades de la provincia de Castellón como Morella o Nules:

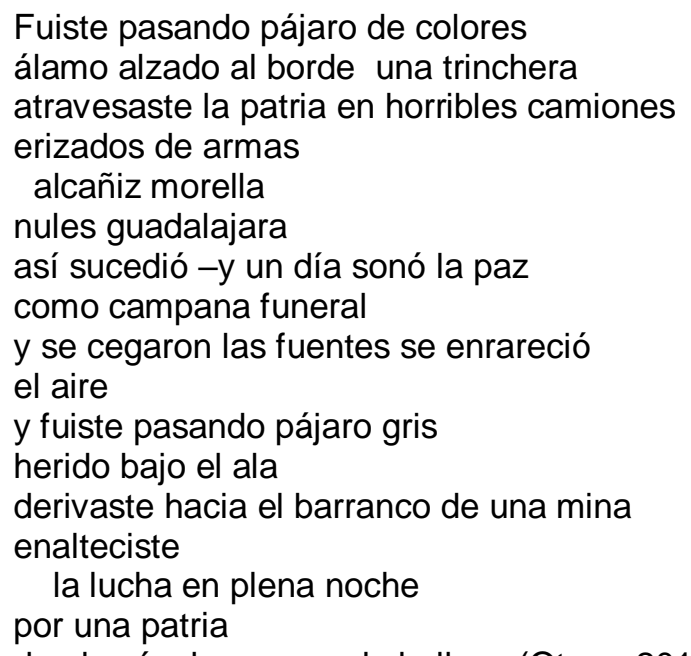

de alegría de acero y de belleza (Otero, 2013: 503-504)

El lance bélico del que habla el poeta, con una mezcla de reconocimiento a su propia vivencia y de tristeza ante cómo "un día sonó la paz", encaja con el avance del bando nacional en la contraofensiva del primer trimestre de 1938 sobre el Bajo Aragón como respuesta a la toma de Teruel por parte del ejército republicano el 8 de enero de 1938 (Thomas, 1976: 851). Bajo el mando de los generales Aranda y Varela, las tropas de Franco tomaron entre el 20 y el 22 de febrero Teruel; pocas semanas después consiguieron avanzar sobre la provincia de Castellón y someter casi sin resistencia Morella el 4 de abril (García Monfort, 2015: 199) hasta llegar a Vinaroz, punto clave para alcanzar el Mediterráneo (García Ferrandis, 2012: 188). El poema de Otero muestra de forma lírica lo que se describe en algunos informes del Cuerpo del Ejército de Galicia:

La carretera que desde Alcañiz conduce a Morella, al llegar a las proximidades de La Pobleta se remonta a $1.019 \mathrm{mts}$. de altitud, y la naturaleza del terreno había permitido establecer una línea defensiva, en su mayor parte subterránea, que bien provista de armas automáticas y artillería de pequeño calibre dominaba por completo el acceso a la provincia de Castellón por dicha carretera. [...] La defensa de Morella estaba encomendada a la CXXIX Brigada Internacional, pero según informe del Comisariado del XXII Cuerpo de Ejército ésta "abandonó precipitadamente las posiciones sin tomar contacto con el enemigo poniendo en grave situación a la Brigada LXXIX de la División Andaluza. El vacío fue cubierto por el $4^{\circ}$ Bón. de la LXI Brigada que huyó pronto ante el fuego de la artillería y de la aviación contagiando con su pánico a las fuerzas de la LXXIX, y que el enemigo entrase entonces en la ciudad". (Salvador Gaspar 1998) 
El "pájaro de colores" se identifica fácilmente con el fuego de la aviación que provocó no solo el retroceso de los soldados republicanos, superados a causa de la debilidad de su sistema defensivo, sino la del propio poeta -que en este caso, sin dudas, se identifica con el sujeto lírico-, quien atravesó la carretera que surcaba algunos puntos montañosos de la comarca del Maestrazgo en unos camiones llenos de armas, "erizados". El avance de los camiones y los aviones se estabilizó a finales de julio de 1938 entre las localidades de Viver y Nules en Castellón (García Ferrandis, 2012: 188-190), que formaban parte de la línea $X Y Z$, que atravesaba sierras y localidades y que constituía una posición defensiva "que començava a l'altura de Nules, vora la mar, seguia per la serra d'Espadà, el Palància, Javalambre i finalitzava a la zona alta del Túria" (Fornas Pallarés, 2016: 207). Finalmente, Nules caería el 8 de julio de 1938, con lo que se rompería la línea defensiva del Ejército Popular de la República, ocupada por la LXXXIII División (Ruiz Manjón-Cabeza, 1986: 606). Poemas como el anterior reflejan la marca indeleble de la lucha fratricida entre españoles, como años más tarde el poeta vasco insinuó en versos pertenecientes a Historias fingidas y verdaderas (1966-1968), Hojas de Madrid con La galerna (1968-1977) o en su autobiografía, Historia (casi) de mi vida (1969):

\begin{abstract}
Al sur de Castellón de la Plana, $4^{\text {a }}$ batería de obuses 149/12, del 12 Regimiento de Artillería Ligera, de Logroño (qué complicado es esto). Algarrobos, cielo azul. Nules. Al otro lado del cerro, Sagunto. Chupinazos a todo pasto. Nos refugiamos en las trincheras, la metralla vuela por todos lados. Una explosión a la entrada de la chabola de los telefonistas. No puedo contenerme y corro hacia allá, pues imagino haya heridos. Los encuentro contando chistes verdes. En mayo nos trasladan al frente de Guadalajara, sembrado de baterías. Se prepara el último golpe contra Madrid. Un mediodía, estando tomando el rancho, vemos aparecer telas blancas en las lomas. La guerra, al carajo, ha terminado. Estamos perdidos lo menos para treinta años. (Otero, 2013: 964)
\end{abstract}

Textos como el anterior, además de poner de relieve que Blas de Otero reflejó en su obra poética en detalle algunos sucesos de la Guerra Civil, suponen una retrospectiva de la propia vivencia y un examen de las consecuencias que la acción individual tuvo en el devenir colectivo. Como indica Lucía Montejo, precisamente al citar el fragmento anterior, el poeta "evoca esos duros tiempos desde el presente, introduce reflexiones actuales (en el tiempo de la escritura)" (2014: 253-254). Este proceso pareció acelerarse 
cuando Otero decidió conocer algunos países del eje comunista durante la Guerra Fría, como la Unión Soviética, Cuba o China ${ }^{4}$ en el primer lustro de la década de los 60 del siglo pasado. Además de Montejo, otros críticos como Mario Hernández han señalado la importancia de ese periodo, pues al poder contemplar el mundo más allá de la España franquista, el poeta comienza a vislumbrar la existencia de un concepto distinto de la patria, mucho más cosmopolita (2013: 48-50), y basado en la propia consciencia que tiene el individuo de la realidad y de sí mismo ${ }^{5}$. De hecho, esta concepción de la patria nace de una mirada en la que convergen dos prismas de la realidad, el histórico y el personal, ya que el reiterado análisis de los hechos del pasado, de la guerra, induce al poeta -y a su prolongación poética- a contemplar de distinta forma su papel en el frente.

Esta salida al exterior se ha conectado con el redescubrimiento de diversos autores por parte de Blas de Otero: Hernández señala una influencia de vital importancia en Otero de las Cartas Marruecas (1789) de José de Cadalso (2013: 49), pues la contemplación del extranjero le permite constatar la decadencia de España, que tal y como señala el ilustrado escritor gaditano en su ficción epistolar, sería una majestuosa casa que se está derrumbando: "Se me figura España desde fin de 1500 como una casa grande que ha sido magnífica y sólida, pero que por el discurso de los siglos se va cayendo y cogiendo debajo a los habitantes" (Cadalso, 1995: 190). Una casa derruida, al igual que un viejo castillo que ya no tiene función alguna. No obstante, a pesar

\footnotetext{
${ }^{4}$ Otero viajó a París en febrero de 1960 para presentar la edición bilingüe de En castellano. Perulero Pardo-Belmonte, gracias a Sabina de la Cruz, señala que dicha presentación fue el 13 de febrero y que "durante esta nueva estancia en París, el poeta recibirá una invitación para viajar a la Unión Soviética y China [...]. No hay demasiada información sobre los meses que pasó en China y la Unión Soviética. El 19 de marzo de 1960, sale del aeropuerto de Orly hacia Praga, según consta en su pasaporte, y llega a Moscú dos días después" (2013: 314). Volvió a París en septiembre de 1960 y a España justo un año después, en 1961. El viaje a Cuba tiene su razón de ser por haber sido seleccionado como jurado del Premio «Casa de las Américas» de 1964 (Perulero Pardo-Belmonte, 2013: 339). No obstante, por diversas cuestiones -entre ellas su matrimonio con la cubana Yolanda Pina- su estancia en la isla se prolongó hasta 1968, cuando vuelve para operarse de un tumor canceroso.

${ }^{5}$ Tal vez este fenómeno se entronque con ciertas características de la autoficción, pues si en esta "el foco de interés se desplaza de los hechos a la identidad de los individuos" (Casas Janices, 2016: 143) parece claro que en algunos poemas de Otero los hechos reales se subordinan a la experiencia del yo lírico. Aunque en este caso cabría cambiar "identidad" por "ideología", pues en Otero el poso comprometido es el predominante y la noción moderna de "identidad" resulta demasiado moldeable al relativismo ideológico.
} 
de la decadencia de la antigua noción de patria vista desde la privilegiada posición del exterior, Otero expresa su añoranza por las gentes y tierras de España:

Buena parte de los poemas que escribe durante estos viajes formarán parte de su libro Que trata de España (1964) con el que cierra el ciclo de tema social, centrándolo en el espacio geográfico de la España de su tiempo. El apartado cuarto reúne algunos de los poemas más bellos sobre el tema de España. Con amorosa delectación toca el paisaje, los nombres de los pueblos, la luz de sus atardeceres, el color de sus piedras, las plazas recónditas (Montejo, 2005: 92).

Los viajes a lo largo y ancho del globo no provocan que Otero reniegue de la patria, sino todo lo contrario. La patria reside en la idiosincrasia del pueblo español, e incluso en su geografía. No parece extraño, por tanto, que la reflexión sobre el tema de España presente concomitancias entre Cadalso y Otero: son dos autores que pasaron importantes periodos de su vida en otros países y que vivieron una experiencia militar decisiva ${ }^{6}$, por lo que su concepto de patria se consolida en ambos a través de la experiencia del viajero y de los rigores de la guerra. Sin embargo, si Cadalso dedicó la mitad de su vida hasta el día de su muerte a su vocación marcial, para Blas de Otero ese paso significó una contingencia indeseada que marcó su vida y su producción poética. Tal y como confiesa el sujeto lírico en "Juventud imbatida", todavía veinte años después se siente responsable del reforzamiento de las viejas ideas, de una paz basada en el sonido de una "campana funeral" y que "enrareció el aire".

Esto provoca la transformación de un conflicto interior en el sujeto lírico, conflicto que ya aparecía en su primera etapa poética, aunque esta estaba cargada de un contenido espiritual: la reescritura de la vivencia, la demostración de la existencia de otra forma de concebir la patria, dan lugar a que Blas de Otero exprese desde los postulados de la poesía social la paradoja del soldado que no deseó ser contendiente. Seguramente, esta singularidad ya se manifestara en los últimos días de su trayectoria militar, incluso en el momento en el que recibió su licencia en Paterna (Lanz, 2016: 37). En todo

\footnotetext{
${ }^{6}$ En el caso de Cadalso, nacido en 1741 y muerto en 1782, permaneció entre 1753 y 1758 , durante su adolescencia, entre Francia e Inglaterra. Más tarde, con 19 años, inició un segundo viaje por Europa, en el que concluyó su educación, de ascendente jesuítico (Palacios Fernández, 2017). Es interesante apreciar cómo en Cadalso existe una huella jesuítica, al igual, por cierto, que en Blas de Otero.
} 
caso, en los años sesenta describe tal fenómeno con una conciencia comprometida y política, deudora del concepto de compromiso sugerido por Sartre $^{7}$. Se observa con claridad en algunos textos pertenecientes a su autobiografía:

Tiempo terrible de la guerra. Te recuerdo en Alcañiz, montados en los horribles
camiones que nos llevaron hasta Vinaroz, bajando junto a Morella y las hoscas
hondonadas de piedra, espino y hierbajos, bajo un cielo duramente azul. ¿Voy a hablar
de la guerra, de esa gran cabronada que nos armaron cuatro militares, ocho
terratenientes y cinco curas, con el respaldo del hijo de puta de Hitler? No, no voy sino
a recordar Bilbao asediado por los requetés, yo en mi batallón vasco, acaso solo por la
fina y triste lluvia que tanto amé siOempre. (Otero, 2013: 954)
El poso del ámbito castrense resuena en los versos oterianos, que traslucen el tormento de la culpa cuando el poeta recuerda las ciudades que visitó en batalla. El resquemor de haber sido un soldado, un "caballero", en el sentido de haber pertenecido a una orden militar o, incluso, en otro sentido todavía menos asumible, el de haber sido responsable -indirecto- de fortalecer el control de los vencedores sobre España, como si de una antigua caballería se tratase ${ }^{8}$, le acompañarán durante toda su vida en sus difíciles y alternantes estados de ánimo. También en su última etapa poética, aunque aborde gustos y filias de índole cotidiana. Ese pesar produce un desencantamiento con todo aquello que recuerde los valores guerreros. $Y$ dicho desengaño exige una reformulación de la experiencia vivida que, en el momento de la enunciación poética, se manifiesta mediante una connotación inesperada del previsible sentido de las palabras elegidas. De nuevo, quizás se pudiera conectar con la autoficción pues en muchos de sus poemas Otero dio "cauce a la experiencia privada [...] evocando a la vez -o transparentando- valores éticos fruto de vivencias compartidas por los miembros de una comunidad" (Casas Janices, 2016: 142). Lo cual se tradujo en la utilización de "narraciones paradójicas" -

\footnotetext{
${ }^{7}$ El compromiso aparece en Jean Paul Sartre durante la Segunda Guerra Mundial, en la que participó en grupos antifascistas. Simone de Beauvoir describe los postulados sartrianos de la siguiente manera: "Su nueva moral, basada sobre la noción de autenticidad y que él se esforzaba por poner en práctica, exigía que el hombre "asumiera" su «situación»; y la única manera de hacerlo era trascenderla comprometiéndose en una acción" (1961: 468). Podría aplicarse este mismo cambio a Blas de Otero, al dejar atrás el lamento metafísico del existencialista propio de su primera etapa poética.

${ }^{8}$ En su vigesimotercera edición el DRAE presenta la siguiente definición en la decimosexta acepción de "caballería": "Porción de tierra que se repartía a los caballeros que habían contribuido a la conquista o a la colonización de un territorio" (2014).
} 
aunque sean textos poéticos- que "transgreden códigos previamente evocados (Casas Janices, 2016: 142).

\section{"El adarve de la almena se ha vuelto gris"}

Tras volver a España en 1968, la poesía oteriana adopta un compromiso "desencantado" con los grandes sistemas, en el que el cambio de noción acerca de la patria deja mayor espacio poético al intimismo, a un discurso sobre las vivencias interiores del hombre. La poética cotidiana exige cambiar, por tanto, la expresión, tal y como ocurre en el poemario póstumo La Galerna, publicado en 2010:

[...] si se compara este poemario con los anteriores de Blas de Otero, más accesibles en cuanto a la configuración de su simbolismo, las diferencias temáticas que se observan son grandes, pues ni aborda explícitamente el deseo de encontrar a Dios de la primera etapa religioso-existencialista, ni la férrea confianza en el colectivo de la época social [...]. (Salvador Salvador, 2018: 93)

El discurso no varía radicalmente en los temas e inquietudes, sino en su perspectiva, lo que requiere trabajar con nuevos instrumentos líricos. Si los castillos se construían por una cuestión estratégica -tomar altura para poder vigilar las posibles acometidas de un enemigo exterior-, la obra que Blas de Otero configuró tras su regreso de Cuba necesitaba tomar altura para potenciar los sentidos de su enunciación poética, para terminar de construir el último nivel del castillo de su poética. Si bien en ocasiones el propio Otero mostró su desacuerdo con el detallismo del estudio filológico ${ }^{9}$, parece confirmado que en su caso "para intentar la aprehensión del mecanismo de una poesía no queda más camino que el análisis de su forma lingüística” (Alarcos Llorach, 1996: 47). De ahí que resulte de interés prestar atención al "contenido significativo dado por los valores de cada vocablo" (Alarcos Llorach, 1996: 48) y atender a las redes extrasintagmáticas que connotan a ciertos vocablos de sentidos inescrutables en un primer momento, pues estos procesos son los que nos

\footnotetext{
9 Por lo general, estudiosos como De la Cruz, Montejo o en tiempos más recientes Terol Becerra (2017: 268) se refieren a uno de los textos más citados de sus prosas poéticas "Reglas y consejos de investigación científica", perteneciente a Historias fingidas y verdaderas en el que Otero escribe: "lo que tú tienes que hacer es dejar de fumar y pasarte la sintaxis por debajo del diccionario" (2013: 617).
} 
llevan al último nivel temático de la obra oteriana: un castillo interior en el que nos adentraremos en sus crisis depresivas (Salvador Salvador, 2018: 94-ss).

En el caso que se analizará a continuación, esta referencia al castillo interior se torna doble, pues el castillo surge directamente de la enunciación. Véase "Diseminado", un poema perteneciente a su poemario La galerna, editado hace menos de diez años, en 2010:

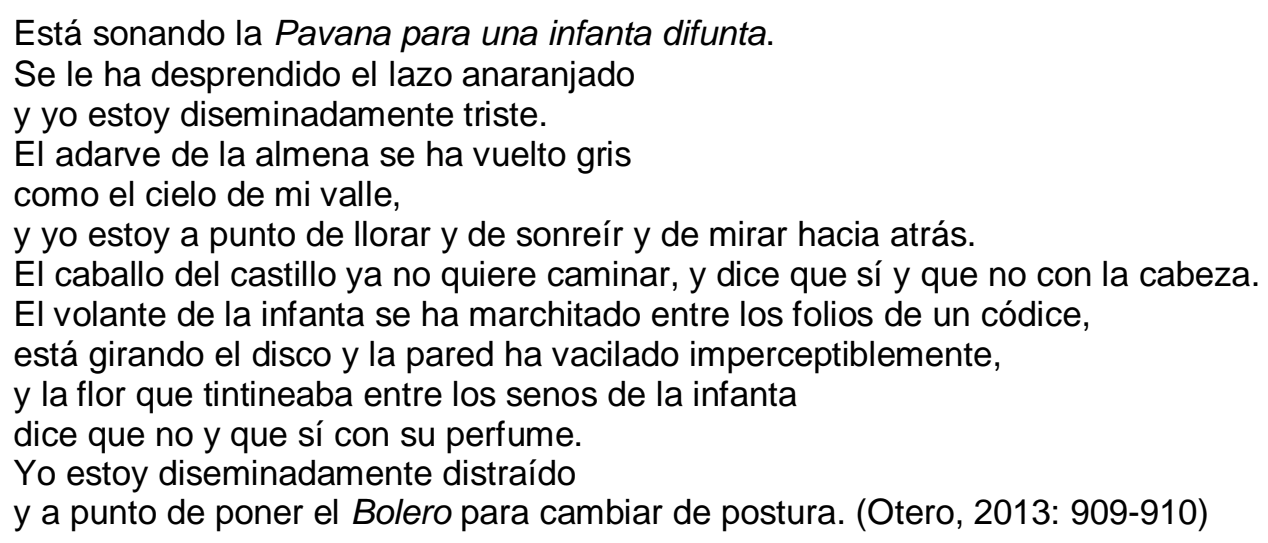

La acción en desarrollo que se describe es sencilla: un hombre triste está escuchando -en un espacio sin concretar- diversas piezas musicales. Sin embargo, esta tristeza viene connotada por una serie de hechos, de índole intra y extratextual, que vienen motivados por el desarrollo biográfico del poeta, que traslada a sus creaciones la desesperación originada por sus crisis depresivas (Lanz, 2016: 40). En comparación con otros poemas de esta última etapa, se aprecia una diferencia importante, pues en "Diseminado" el yo lírico no se desdobla, tal y como ocurre en "Cantar de amigo" (Otero, 2013: 766-767) o "No me arrepiento" (Otero, 2013: 917). Tal aspecto repercute en un tono confesional menos marcado, pero el uso de la primera persona del singular con el verbo "ser" indica el estado del sujeto lírico: "estoy diseminadamente triste", "estoy a punto de llorar y de sonreír y de mirar hacia atrás". Dentro del texto, resulta muy interesante apreciar tres características esenciales del poema: la primera es la ambientación en el castillo. La segunda, la especificación de qué piezas musicales está oyendo el sujeto lírico, para terminar de configurar su estado anímico. La tercera, y derivada de las anteriores, la fragmentación espacio-temporal que invade todo el poema, la cual, además, está representada mediante una superposición de planos en los que se confunden 
la acción vivida por el sujeto lírico y la fantaseada. O, más bien, habría que señalar, se superpone el plano de lo real al plano de lo imaginado.

La ambientación en el castillo se caracteriza por la selección de un determinado campo ideológico o nocional ${ }^{10}$. Aparecen en el texto elementos tales como una infanta, un adarve, una almena, un caballo, un códice, un castillo... En las primeras lecturas, el mensaje que descodifica el lector resulta más sencillo de comprender cuanto más accesible sea la conformación sémica de su significado ${ }^{11}$. En este caso, quizás las apalabras que más dificultades presenten, por pertenecer a un vocabulario más específico, sean "almena" o "adarve", pero una vez aprehendidas, parece fácil percibir el tipo de ambientación del plano imaginado.

Resulta importante centrarse en el uso del campo ideológico al que pertenece "castillo", seguramente el de lo épico. El texto subvierte el carácter ardoroso y bélico que se le supondría a dicha selección léxica. No parece atisbarse ningún rastro de heroicidad cuando se mencionan elementos tales como la infanta difunta, el esperpéntico caballo que no sabe qué decir o el volante que se marchita al tocar las páginas de un códice. Todos estos elementos están dispuestos en el texto en medio de una situación extraña, difícil de definir, de fuerte carga onírica. Tampoco hay rastro de un caballero, de un lance bélico revestido de energía y honra, sino que, incluso, el campo ideológico escogido no deja de ser un elemento secundario que busca enfatizar la situación primaria: el estado de un hombre que oye música. No parece que pueda haber nada menos bélico o combativo que la situación expuesta.

Esta sensación se acentúa al examinar las piezas musicales que aparecen en "Diseminado"; la elección no deja de tener una clara intención:

\footnotetext{
${ }^{10}$ El campo ideológico o nocional es un conjunto de formas léxicas que pertenecen a un mismo ámbito de realidad y que, precisamente por eso, se asocian en la memoria de quienes tienen la experiencia o el conocimiento de tal ámbito. Este modelo de red asociativa fue propuesta por Georges Matoré (1908-1998), quien señaló en su libro La méthode en lexicologie (1953) sobre dichos campos que "las palabras tienen una existencia social, se encuentran relacionadas sintagmáticamente en el contexto y, fuera de él", (Casas Gómez, 2015: 24). Por ejemplo, "médico", "bata", "enfermera", "fonendoscopio", "jeringuilla", "suturar", "cura", "medicación", "cama", "camilla", "quirófano"... formarían parte de un mismo campo ideológico.

${ }^{11}$ Adapto -parafraseo- a este análisis poético la siguiente apreciación: "la relación entre grado de complejidad del significado y accesibilidad tampoco requiere demasiadas explicaciones. Es natural que una palabra resulte tanto más asequible al entendimiento cuanto más simple sea la configuración sémica de su significado" (Salvador Rosa, 2004: 63).
} 
crear un ambiente melancólico. La pieza que va sonando a lo largo de la acción descrita en el poema es una "pavana", una pieza musical procesional, de estilo elegante y serio ${ }^{12}$. Además, es una pieza musical en concreto, La pavana para una infanta difunta compuesta por Maurice Ravel en 1899 y cuyo título sugiere que está dedicada a un muerto. Es decir, el plano imaginado surge de una experiencia real desoladora, de ahí que Otero indique en el verso tres: "y yo estoy diseminadamente triste"13. "Diseminar" quiere decir espaciar, por lo que el sujeto lírico está esparciendo lo que ya estaba junto: su estado de ánimo existía de antes y ahora se expande hasta su mundo imaginado, lo que, versos más tarde, explica que el adarve de la almena se haya vuelto gris. A partir de la música se da la fragmentación entre diferentes espacios, tiempos y sujetos. El carácter taciturno del poema es incontestable pues, como se ha apuntado anteriormente, la imagen de lo militar pierde vigor. La protección que daba la almena, un muro que funciona como fortaleza, se resquebraja y su cromaticidad se compara a la del "cielo de mi valle". La llanura, un espacio firme y amplio, se ve teñido de un color que no parece anticipar una transformación de índole positiva. De hecho, la metamorfosis que sufre el sujeto lírico en el plano real es mucho más terrorífica, pues en la habitación está "a punto de llorar y de sonreír y de mirar hacia atrás". Al manifestar esa oscilación anímica, se pasa al plano imaginado para mostrar que quien le abre el camino al caballero, el caballo, está aturdido: "El caballo del castillo ya no quiere caminar, y dice que sí y que no con la cabeza". Si el caballo tampoco puede avanzar, el tiempo de las hazañas ha llegado a su fin. Pero no extraña nada en ese castillo oteriano, pues el adarve se vuelve gris o los códices marchitan volantes de infantas que están muertas.

Llegado a este punto, al constatar esa diferencia entre el plano de lo real y el plano de lo imaginado, cabe preguntarse por qué el sujeto lírico -al que se podría identificar con el poeta, tal y como señala Juan José Lanz, cuando

\footnotetext{
12 Comenta Miroslava Sheptak en su Diccionario de términos musicales lo siguiente: "antigua danza lenta de origen italiano; lo mismo que padovana o paduana" (2014: 90). EI DRAE en su primera acepción: "danza española, grave y seria y de movimientos pausados" (2014).

${ }^{13} \mathrm{La}$ idea ya se ha apuntado en un análisis de La galerna: "Además, la Pavana para una infanta difunta resulta ser el detonante de la bifurcación temporal llena de desesperación de «Diseminado»" (Salvador Salvador, 2018: 104).
} 
apunta que muchos de estos últimos poemas funcionarían a modo de una "terapia psicoanalítica" (2016: 40-41)- nos describe una ensoñación radicada en un castillo. En primer lugar, parece claro que el castillo da cabida a un elemento simbólico que cabría relacionar con un tema fundamental del conjunto poemático al que pertenece, La galerna, el caos vital que "muestra la depresión y el desmoronamiento físico del sujeto lírico" (Salvador Salvador, 2018: 94). En segundo lugar, la elección del castillo en sí misma se constituye como un elemento simbólico que hay que tener en cuenta. Al principio de este artículo se hizo mención al prototipo de literato que relacionaríamos con los castillos y se nombró a santa Teresa de Jesús. Algunos valores simbólicos de raigambre religiosa que aparecen en la obra teresiana se pueden palpar en Blas de Otero, ya solo atendiendo a la formación religiosa de este último ${ }^{14}$. Si en las Moradas resuenan los ecos de una famosa sentencia bíblica -"El Señor es mi ayuda y mi castillo, mi protección y mi salvador" (Salmo 144)-, en "Diseminado" aparece un castillo en descomposición, en el que el sujeto lírico permanece desconcertado. Este problema, que se podría explicar por la pérdida de fe tanto en Dios como en los grandes sistemas, no es baladí. Por ejemplo, la ambientación épica o incluso medieval del plano imaginado en el poema oteriano tiene sus raíces en la memoria cultural de Occidente, ya que durante el medievo "las ciudades amuralladas aparecen [...] como símbolo del alma en su trascendencia y de la Jerusalén celeste" (Cirlot, 1988: 121). De hecho, el propio Cirlot apunta que "su forma, aspecto y color, su sentido sombrío y luminoso tiene gran valor para definir la expresión simbólica del castillo, que en el sentido más general es una fuerza espiritual armada y erigida en vigilancia" (Cirlot, 1988: 121). Como se observa en el poema, el castillo es capaz de trasladar su tono decaído, grisáceo, al cielo, sensación que se desplaza al plano real puesto que el sujeto lírico carece de fuerza, al sentirse anegado por las crisis depresivas. Además, el juego entre el plano real y el imaginario se sirve del castillo como símbolo de la desorientación interior, pues

\footnotetext{
${ }^{14}$ No solo santa Teresa, por supuesto, ya que el motivo del castillo aparece en gran parte del imaginario judeocristiano: "La contemplación de una fortaleza en el sentido simbólico es un fenómeno especialmente occidental” (Biederman, 1993: 94-95).
} 
este también simboliza "el inconsciente, la memoria confusa" (Morales y Martín, 1984: 89).

Con todo, parece que la selección del castillo como escenario del plano de lo imaginado no solo obedece a la ambientación y a la simbología expuesta en el párrafo anterior, sino a los "sentidos"15, a los valores que el campo ideológico o nocional de lo épico, al que pertenece, puede incluir. Este campo se constituye porque sus términos hacen referencia a objetos y sujetos que coinciden en situaciones, por lo que parece posible que tal grupo esté destinado a crear una ambientación determinada, un espacio épico, del que, con el paso de los versos, el sujeto lírico va a expresar algo aparentemente incompatible con él. Es el propio texto el que, en primer lugar, convierte al campo nocional en la médula del contenido, aunque siempre subordinado al plano de lo real, en el que el sujeto lírico está "diseminadamente triste". Esta subordinación es la que nos sugiere una connotación del campo ideológico de lo épico a través de un factor extraliterario que se manifiesta en otros poemas: parece claro que el resabio del soldado en el frente levantino, visto en "Juventud imbatida", pervive en ese campo ideológico, y que refuerza la situación de desasosiego descrita en "Diseminado". De esta manera, este poema presenta un procedimiento de filiación entre las cosas particulares reinterpretadas por la vivencia y el léxico que las nombra. Este proceso poético provoca que ciertas palabras tengan unos rasgos significativos de corte extralingüístico.

\section{Conclusión}

Sin embargo, el final del poema da lugar a un cambio aparentemente inesperado, pues entre esos adarves que se podrían suponer erizados, al recordar "Imbatida juventud" -"horribles camiones / erizados de armas"-, surge la música como elemento transformador y capaz de modificar las concomitancias que hemos visto entre el plano real ("el hombre en un espacio escuchando música") y el plano imaginado ("el castillo"). Y es que, a pesar de que el sujeto lírico del poema haya renunciado a seguir los caminos de lo épico

\footnotetext{
${ }^{15}$ Véase nota 2.
} 
y aparezca superado por la realidad, anuncia que va a cambiar la pieza que suena: "Yo estoy diseminadamente distraído / y a punto de poner el Bolero para cambiar de postura". Aunque siga estando diseminado, disperso, la música del futuro es mucho más impetuosa que la de la pavana. Se supone que a continuación sonará el Bolero de Ravel: la pavana que sonaba la compuso el músico francés y el Bolero quizás sea su pieza más conocida. Además, la fascinación por dicha composición se observa en la última etapa poética de Blas de Otero ${ }^{16}$. Así pues, la pieza lenta va a ser sustituida por otra que se caracteriza por un ritmo machacón y obsesivo, pero que posee una gran fuerza musical y una energía mucho más vigorosa.

"Diseminado" es una muestra del castillo interior oteriano, en el que acaban convergiendo desde sus miedos más íntimos y cotidianos hasta los resabios de épocas más oscuras para el poeta vasco. La connotación negativa del campo ideológico de lo épico aparece al mismo tiempo como un motivo textual y como un eco de la memoria. Esta tiene como una de sus funciones la captación de información, y esta información acumulada por el sujeto es la que se manifiesta en la lectura profunda del corpus poético, al relacionar cuestiones intra y extraliterarias. Aquí residiría la configuración de lo poético por parte del poeta:

Lo poético viene [...] cuando el poeta analiza esas sustancias de contenido y las va configurando poéticamente. [...] las une con formas de expresión justas y necesarias, de modo que se adaptan a la esencia última y profunda de sus experiencias personales, vistas desde una particular perspectiva dentro de inevitable decurso temporal. (Alarcos Llorach, 1996: 183)

Pero más allá de los posibles sentidos de los elementos que habitan en el texto, es importante acabar volviendo al castillo interior del sujeto lírico, del poeta, en el que la música nos enseña que a pesar de los múltiples elementos negativos y de las quiebras interiores del espíritu, todavía queda hueco para la esperanza. En conclusión, la futura música del Bolero nos recuerda, que como escribió el propio Blas de Otero, "de un solo verso nacen multitud de paréntesis, soldados y otras cuestiones" (2013: 613). Tanto para el "vividor" de esa poesía como para su receptor.

\footnotetext{
${ }^{16}$ Prueba de ello son los poemas "El bolero de la historia", de La galerna (2013: 915-916), y "El Bolero", de Hojas de Madrid (2013: 823).
} 


\section{BiBLIOGRAFÍA}

Abad Nebot, Francisco [2011] (2014). Presentación de la semántica. Madrid: Editorial Centro de Estudios Ramón Areces.

Alarcos LloRACH, Emilio (1996). Blas de Otero. Oviedo: Ediciones Nobel.

BeAuvoIR, Simone de (1961). La plenitud de la vida. Buenos Aires: Sudamericana.

Biederman, Hans (1993). Diccionario de símbolos. Barcelona: Pairós.

CADALSO, José de [1789] (1995). Cartas marruecas. Noches lúgubres. Joaquín Arce (ed.). Madrid: Cátedra.

CASAS GÓMEZ, Miguel [1999] (2015). Las relaciones léxicas. Tübingen: Niemeyer.

CASAS JANICES, Ana (2016). "Narrativas de las (pos)memorias: autoficción, subjetividad y emociones", Letras Hispánicas: Revista de Literatura y de cultura, vol. 12, 1, pp. 139-153.

CIRLOT, Juan Eduardo (1988), Diccionario de símbolos. Barcelona: Labor.

COSERIU, Eugenio (1978). Gramática, semántica, universales. Madrid: Gredos, Biblioteca Románica Española.

CRuz, Sabina de la (2013). "La vida de un poeta". En Sabina de la Cruz (ed), Obra completa. Barcelona: Galaxia Gutenberg, pp.57-77.

EscANDELL VIDAL, María Victoria (2004). Fundamentos de semántica composicional. Barcelona: Ariel.

FERNÁNDEZ DE LA SOTA, José (2016). "Blas de Otero, retrato discontinuo", Campo de Agramante: revista de literatura, 25, pp.37-44.

Fornas PALLARES, Alfredo (2016). Un somni truncat per les bombes. Segona República i Guerra Civil a l'Alacalatén. Tesis doctoral dirigida por Rosa Monlleó Peris. Castellón de la Plana: Universitat Jaume I, en https://www.educacion.gob.es/teseo/imprimirFicheroTesis.do?idFichero= GOZgwlhe\%2F\%2BU\%3D [Fecha de consulta: 14 de enero de 2019]

GARCía FERRANDIS, Xavier (2012). "La cobertura sanitaria de un ejército en retirada", Sanidad militar: revista de sanidad de las Fuerzas Armadas de España, 68, 3, pp.197-192.

GARCíA MONFORT, Marta (2015). "La depuración del magisterio nacional en Morella (1936-1945)", Pasado y Memoria: Revista de Historia Contemporánea, 14, pp.197-225.

HERNÁNDEZ Mario (2013). "Palabras vivas". En Sabina de la Cruz (ed), Obra completa. Barcelona: Galaxia Gutenberg, pp. 7-54.

LANZ, Juan José (2016). "Blas de Otero «en canto y alma»: En el centenario de su nacimiento", Poéticas: Revista de Estudios Literarios, 2, pp. 27-61

LEECH, Geoffrey (1985). Semántica. Madrid: Alianza.

MONTEJO, Lucía (2005). "Blas de Otero en la revista Papeles de Son Armadans", Epos: revista de filología, 30, pp. 247-260.

MONTEJO, Lucía (2014). "La prosa autobiográfica de Blas de Otero, Historia (casi) de mi vida (1969): La construcción de la subjetividad", Epos: revista de filología, 20-21, pp. 85-99.

MORALES y MARín, José Luis (1984). Diccionario de iconografía y simbología. 
Madrid: Taurus.

OtERo, Blas de (2013). Obra completa. Barcelona: Galaxia Gutenberg.

PALACIOS FERNÁNDEZ, Emilio (2018). “José Cadalso y Vázquez". En Diccionario Biográfico Español, en http://dbe.rah.es/biografias/9723/jose-cadalso-yvazquez [Fecha de consulta: 14 de enero de 2019].

Perulero Pardo-Belmonte, Elena (2013). La poesía histórica de Blas de Otero. Tesis doctoral dirigida por Selena Millares. Madrid: universidad Autónoma de Madrid, en https://repositorio.uam.es/bitstream/handle/10486/660389/perulero_pard o_belmonte_elena.pdf?sequence=1 [Fecha de consulta: 14 de enero de 2019].

Real Academia Española (2014). Diccionario de la lengua española, en http://dle.rae.es/?w=diccionario [Fecha de consulta: 13 de enero de 2019].

RuIz MANJón-CABEZA, Octavio (1986). Historia general de España y América, tomo XVII. Madrid: Ediciones Rialp.

SALVADOR GASPAR, Manuel (1998). "Año 1938. Operaciones militares en la provincia de Castellón", Boletín de la Sociedad Castellonense de Cultura, LXXIV, en http://www.aulamilitar.com/pagiht74.htm [Fecha de consulta: 14 de enero de 2019].

SALVADOR RoSA, Aurora (2004). "La enseñanza del léxico: reflexiones y propuestas didácticas". En J.A. Moya Corral y M.I. Montoya Ramírez (eds.), Variaciones sobre la enseñanza de la lengua. Actas de las IX Jornadas sobre la enseñanza de la lengua española. Granada: Editorial Universidad de Granada, pp. 49-66.

SALVADOR SALVADOR, Julio (2018). "Análisis de La galerna, poemario tardío de Blas de Otero", Siglo XXI. Literatura y Cultura Españolas, 16, pp.87-110

SHEPTAK, Miroslava (2014). Diccionario de términos musicales. Madrid: Paraninfo.

TERol BeCERRA, María Dolores (2017). Hacia un replanteamiento de la poesía social: el caso de Blas de Otero. Tesis doctoral dirigida por Manuel Ángel Vázquez Medel. Sevilla: Universidad de Sevilla, en https://idus.us.es/xmlui/bitstream/handle/11441/61167/tesis_maria_dolor es_terol_blas-otero.pdf?sequence $=1$ [Fecha de consulta: $1 \overline{4}$ de enero de 2019].

ThOMAS, Hugh (1976). Historia de la Guerra Civil Española. París: Ruedo Ibérico.

Fecha de recepción: 15 de enero de 2019

Fecha de aceptación: 26 de febrero de 2019 